\title{
USAIN BOLT COMO ENTIDADE ENUNCIATIVA: A CONSTRUÇÃO DE SUA MARCA PESSOAL NO CONTEXTO DAS OLIMPÍADAS DE 2016
}

\author{
Usain Bolt as enunciative entity: the construction of his \\ personal brand in the context of the 2016 Olympics \\ Usain Bolt como autoridad de enunciación: la construcción de su \\ marca personal en el contexto de los Juegos Olímpicos de 2016
}

\author{
Rafael dos Santos Hönig \\ Universidade Federal de Santa Maria, Rio Grande do Sul, Brasil. \\ Acadêmico de Comunicação Social, habilitação em Publicidade e Propaganda pela Universidade Federal de \\ Santa Maria. Integrante do grupo de pesquisa "Estratégias da produção midiática dos sentidos". \\ E-mail: rafaelhonig@gmail.com
}

\section{Fabiano Maggioni}

Universidade Federal de Santa Maria, Rio Grande do Sul, Brasil.

Doutor e mestre em Comunicação Midiática pelo Programa de Pós-Graduação em Comunicação da Universidade Federal de Santa Maria. Professor adjunto do curso de Publicidade e Propaganda da Universidade Federal de Santa Maria. Pesquisador na área de imagem e semiótica.

E-mail: fabiano@ufsm.br

\author{
Magnos Cassiano Casagrande \\ Universidade Federal de Santa Maria, Rio Grande do Sul, Brasil. \\ Doutorando em Comunicação Midiática do Programa de Pós-Graduação em Comunicação da Universidade \\ Federal de Santa Maria. \\ E-mail: magnoscassiano@yahoo.com.br
}

RESUMO A partir da lógica de como são criadas as marcas na contemporaneidade, busca-se analisar como o atleta Usain Bolt constrói sua marca pessoal nas competições e locais onde participa. Utilizando como base a obra de Semprini, explana-se acerca das características de marcas na contemporaneidade e trabalha-se a questão de marca pessoal - aqui denominada me brand. Parte-se do projeto de marca proposto pelo autor que é adaptado ao atleta. Em seguida, como método de análise, utiliza-se a tríade sobre valores, narração e discursos.

PALAVRAS-CHAVE Me brand, Comunicação, Marca, Semiótica.

ABSTRACT Based on the logic of how brands are created in the contemporary world, this project seeks to analyze how the athlete Usain Bolt builds his personal brand in the competitions and places where he participates. Using as a basis the work of Semprini, it explores the characteristics of contemporary brands and the question of personal branding - here called "me brand" -, starting with the brand project proposed by the author adapted to the athlete. Then, as a method of analysis, the triad values, narration, and speeches is used.

KEYWORDS Me brand, Communication, Brand, Semiotic.

RESUMEN Con la lógica de cómo se forman las marcas en la contemporaneidad, buscamos analizar cómo el atleta Usain Bolt construye su marca personal en competiciones y en locales donde participa. Utilizando como base el trabajo de Semprini, explicamos las características de la marca contemporánea y trabajamos la cuestión de la marca personal -aquí se llama me brand. Se parte de la marca propuesta por el autor del proyecto, que se adapta al atleta. A continuación, se utiliza un método de análisis en tríada, valores, narración y discursos.

PALABRAS CLAVE Me brand, Comunicación, Marca, Semiótica. 


\section{A MARCA NA CONTEMPORANEIDADE}

É notório que ao longo do tempo foram propostas diversas conceituações referentes à marca. A mais usual é a desenvolvida pela American Marketing Association, citada por Kotler (1998, p. 393): "Um nome, termo, sinal, símbolo ou combinação dos mesmos, que tem o propósito de identificar bens ou serviços de um vendedor ou grupo de vendedores e de diferenciá-los de concorrentes”. Apesar de não se deter muito às subjetividades, a explicação torna possível o pensamento de algo que visa representar algo maior, ou referenciando a clássica definição de signo da semiótica peirceana - "algo no lugar de algo".

Martins (2006, p. 8), de certa forma, amplia o conceito. Segundo o autor, "uma marca é a união de atributos tangíveis e intangíveis, simbolizados num logotipo, gerenciados de forma a criar influência e gerar valor". A marca é um sistema integrado que promete entrega de soluções desejadas pelas pessoas. Conquanto, apesar de considerá-las representadas por um logotipo, evidencia a existência de um sistema capaz de gerar valor - o que nos possibilita a um pensamento de circunstâncias relacionais.

Essas definições certamente acabam por convergir em aspectos semelhantes de uso. Mas Perez (2004, p. 10), após fazer um breve debate acerca da vastidão de conceituações, acrescenta uma nova interpretação: "é uma conexão simbólica e afetiva estabelecida entre uma organização, sua oferta material, intangível e aspiracional e as pessoas para as quais se destina”. As marcas então não são apenas um produto, mas algo perceptual. A definição, composta por questões simbólicas, nos torna capazes de sustentar uma discussão sobre a própria atuação das marcas.

Entretanto, o debate mais adequado para este artigo é trazido por Semprini (2006). Ao discutir a marca na contemporaneidade, o autor considera três dimensões que a caracterizam: A natureza semiótica, sendo a intenção como objeto semiótico enunciador de produzir significados relevantes e atraentes; a natureza relacional sendo a necessidade de manter uma unidade no discurso na sua relação com o consumidor e no contrato da comunicação; e a natureza evolutiva destacada como a importância de as marcas serem capazes de mudar e se adaptar ao ambiente onde se encontram.

Sendo assim, a forma como o mecanismo de funcionamento de uma marca é colocado nessas dimensões pode levar o público à identificação de suas manifestações, bem como são capazes de diferenciá-la e construir um vínculo emocional com elas. Na competição mercadológica atual, é visto que isso se torna quase que uma meta a ser alcançada pelas marcas para que não caiam na fragilidade e no esquecimento.

Ao buscar a diferenciação em forma de discursos, uma marca propõe uma série de enunciados que produzem sentidos. Casaqui (2009) diz que a linguagem publicitária desenvolve representações que constroem o universo simbólico das marcas. Logo, as mercadorias que são colocadas à disposição dos consumidores são percebidas por uma identificação com estilos de vida, comportamento e atribuições de qualidade, além de gerarem uma diferenciação e superioridade em relação a uma concorrência.

A linguagem é a parte que ajuda a marca nesse intenso processo. Hoje, mais do que nunca, uma marca encontra como obstáculo uma quantidade enorme de outras que também buscam um lugar na mente dos consumidores. As informações tornam-se cada vez mais dispersas e demasiadas - o que torna o processo de conquista de consumidores e de mercado algo extremamente desafiador. 
Para tanto, diz Semprini (2006, p. 106): “o poder semiótico da marca deve consistir em saber selecionar os elementos no interior do fluxo de significados e organizá-los em uma narração pertinente e atraente para propô-los a seu público”. Mas, segundo o autor, não apenas. A fidelidade em relação aos discursos da marca deve ser reforçada, buscando a manutenção de situações relacionais.

Desse modo, a marca torna-se uma resultante de trocas e negociações entre o polo da produção (instância que detém o direito de enunciação fundamental), o polo da recepção (quem lê, interpreta, filtra e avalia), e o polo do contexto geral (onde se organiza o processo de troca entre 0 polo da produção e o polo da recepção).

O contexto geral está em constante transformação e impõe tendências simbólicas e culturais. As tendências se ignoradas trazem o risco do enfraquecimento e, até mesmo, da obsolescência da marca. Tendo esse conhecimento, a marca busca a dimensão contratual, quando finalmente se firma a noção de fidelidade. Assim as trocas entre os polos devem ser apresentadas sob certa regularidade e continuidade temporal.

Já a terceira dimensão da marca na contemporaneidade - a natureza evolutiva - traz como característica seu aspecto mutável e dinâmico. Uma marca deve manter uma contínua evolução porque as tendências sociais assim o pedem. Situações como a mudança dos desejos dos clientes e as modificações da empresa podem aparecer. Portanto, é necessário reagir diante desse cenário turbulento, adaptando e reafirmando sua dimensão evolutiva.

Essas dimensões apresentadas nos ajudam a perceber quão complexo é a construção de um projeto de marca hoje e que, pelo dinamismo e evolução contextual, surgem possibilidades de recriação dessa lógica nos mais diversos locais. $O$ cenário proporcionado pela competição estimula a criação de estratégias, fazendo que pessoas também apliquem essas lógicas para usarem como atributo pessoal.

Seja por pessoas comuns ou celebridades apresentar-se como diferente hoje se torna um dos requisitos para conseguir a atenção dos demais. Neste artigo, utilizar-se-á como exemplo de marca o velocista Usain Bolt. Tendo como base o projeto de marca proposto por Semprini (2006), buscase analisar como o atleta se constrói nas corridas que participa, e como se insere no conceito de Me brand. Mas antes, cabe aqui colocar uma breve definição e contextualização desse termo.

\section{O ME BRAND}

O debate acerca do fenômeno ainda faz-se pouco presente. É difícil datá-lo com precisão, visto que o acesso às tecnologias e às redes sociais torna a percepção confusa acerca de sua primeira aparição. Arruda (2015) considera que os primeiros relatos vieram com as camgirls, que faziam a transmissão de seu cotidiano na rede. Elas ligavam as webcams, falavam sobre seu dia a dia e interagiam com os espectadores. Essas garotas segmentavam suas características de acordo com a audiência, construindo-se como marca pela exibição de um "eu" personalizado.

Desde então, é possível perceber que é cada vez mais comum essas manifestações na internet. Sejam pelos professores que visam a um público fora da sala de aula, por exemplo, de jovens que gravam vídeos manifestando suas opiniões, ou pessoas que utilizam blogs e redes sociais para falarem sobre determinado tema. As marcas estão em todos os lugares, mesmo que não bem definidas. 
O blog Plann refere-se ao fenômeno dizendo que "Uma Me Brand geralmente é centrada, liderada em uma pessoa que transforma seu talento, conhecimento ou conteúdo em um portfólio de negócios baseado em branding”. São negócios que compõem o pensamento de "monetização" e "influência" como estratégia de branding. De acordo com o site, o termo diz respeito às pessoas que utilizam as mídias sociais como forma de propagação de marca.

Todas essas referências dizem respeito às microcelebridades no ambiente digital. No entanto, o mundo do esporte engloba atletas cujas marcas tornam-se muito valiosas. O tenista suíço Roger Federer é exemplo. Segundo o ranking anual da lista Forbes "Fab 40", que visa calcular o valor de marcas relacionadas ao esporte, o atleta faz parte dos dez atletas com as marcas mais valiosas do mundo em 2016 (OZANIAN, 2016).

O tenista faturou cerca de 68 milhões de dólares em 12 meses e possui o valor de sua imagem estimado em 36 milhões. Outros atletas mais conhecidos encontram-se também na lista, como Lionel Messi e Cristiano Ronaldo, ambos jogadores de futebol. Usain Bolt ficou em quarto lugar, com um valor estimado em 25 milhões de dólares.

É parte que as constatações nos conferem a capacidade de ampliar o uso do termo me brand para os atletas. Bolt, nesse contexto, nos apresenta adjetivos ainda mais expressivos, uma vez que proporciona aspectos singulares e performáticos de apresentação. Apesar de não utilizar como foco principal a exibição de marca nas redes sociais e na internet, oferece a manifestação de discursos nas pistas e fora delas, o que nos leva a debater acerca de sua relevância para o estudo.

\section{USAIN BOLT}

Usain Bolt é um velocista jamaicano multicampeão mundial e olímpico. Considerado o homem mais rápido do mundo, foi o único atleta a ser tricampeão em duas modalidades de pista em Jogos Olímpicos consecutivamente (100 e 200 metros rasos) e bicampeão na modalidade revezamento (4 x 100 metros). Foi também o único a conquistar oito medalhas de ouro em provas de corrida.

Todas as conquistas o fizeram ser chamado de Lightning Bolt ("raio") e contribuíram para que se tornasse um dos atletas mais memoráveis do mundo. Criou sua marca registrada, quando, ao final das corridas, executa uma pose de raio com os braços (Figura 1).

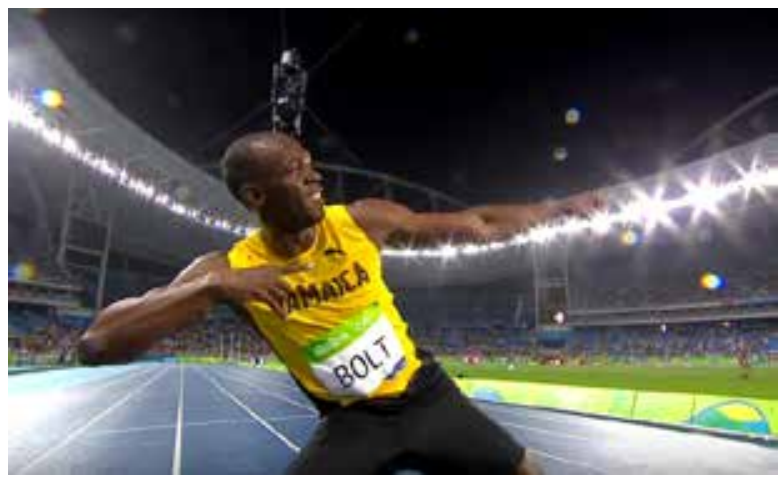

Figura 1. Bolt na corrida de 200 m, Olimpíadas Rio 2016. Fonte: YouTube, 2016!

1. Disponível em: <https://goo.gl/dgGHWm>. Acesso em: $1^{\circ}$ fev. 2018. 
Acostumando o público a seus comportamentos, viu-se que Bolt construiu aos poucos sua imagem pessoal. Ao entrar nas pistas, dançava, pedia às pessoas que fizessem barulho, em seguida pedia que fizessem silêncio. Comumente, ao final de sua performance, fazia o sinal da cruz e a execução de sua pose característica. Em uma entrevista a ESPN, brincou com o repórter enquanto este estava transmitindo as informações. Em outra, interrompeu a jornalista para ouvir o hino nacional dos Estados Unidos. Também teve uma passagem pela escola de samba do Salgueiro, onde sambou e interagiu com as dançarinas (MOTA, 2016).

A execução de sua pose passou a ser praticada pelo público e até mesmo por outros atletas. O jogador de futebol Neymar, ao fazer a comemoração de seu gol em uma partida entre Brasil e Alemanha, fez a pose característica da comemoração de Bolt. Fatos repercutiram nas redes sociais em questão de minutos, e Bolt se tornou um dos assuntos mais comentados do Twitter.

$\mathrm{O}$ atleta também destacou-se em propagandas, como no storytelling criado pela marca Gatorade (PARA..., 2016), que conta sua história desde a época de criança até a atualidade. O audiovisual criado em forma de desenho foi intitulado como "O menino que aprendeu a voar". No Facebook da página brasileira de Gatorade, até outubro, houve cerca de 8,6 mil curtidas, 1,3 mil comentários e 23.660 compartilhamentos.

O audiovisual mostra Bolt, ainda criança, correndo para não chegar atrasado na escola. Conta sua trajetória, como começou a correr e todas as dificuldades pelas quais passou. É possível encontrar uma série de frases motivacionais ao longo do vídeo como "você pode ir sempre mais rápido quando está leve” e frases que levam a ideia de superação como "uma vida de suor".

Cabe também destacar o fato de ter sido um dos porta-vozes da marca do Banco Original. O atleta foi homenageado com sua imagem e assinatura gravados no cartão Gold 9.58. Nas propagandas, utilizava sempre palavras impactantes e provocadoras, como "nos últimos dez metros, ninguém me pega" e "eu sou o cara”.

Por meio dessas e demais manifestações, apoiou-se em ideias como descontração, excentricidade e intimidação. Ajudou a criar um cenário onde ficou livre para mostrar sua personalidade. Comentado pelo mundo todo por suas ações, fica evidente que o atleta gerou uma identificação por parte dos espectadores. $O$ resultado aparece no afeto, carinho e respeito daqueles que 0 assistiram.

\section{USAIN BOLT COMO ENTIDADE ENUNCIATIVA}

A partir de agora, falaremos sobre o projeto de marca proposto por Semprini, relacionando-o a Bolt. Em seguida, veremos sobre as manifestações da marca e como o atleta trabalha com elas organizandoas em valores, narrativas e discurso. Apresentaremos então, brevemente, uma contextualização, seguido da explicitação de como se dá a organização do projeto de marca e como ela dá suporte para que então os enunciados se concretizem.

Primeiramente, para Semprini (2006, p. 73), há vínculos evidentes das lógicas de marca com as dimensões imaterial e de imaginário: 
A capacidade de construir mundos, desenvolver territórios simbólicos e manipular a abstração são aspectos que definem a lógica de marca. O desenvolvimento, no seio do consumo, de dimensões imateriais e imaginárias, entra então em íntima ressonância com a própria essência da lógica de marca.

Por esse viés, pensando a marca como instância eminentemente semiótica, sua intenção de comunicação se transforma sempre em enunciado. A marca coloca-se como instância enunciativa no topo do ato enunciativo e controla as condições, produzindo enunciados concretos. O esquema apresentado por Semprini é definido por esse contexto fundamental e nos ajuda a sustentar a análise de Bolt como marca.

Entremos, então, no projeto proposto por Semprini representado na Figura 2.

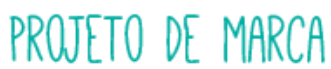

\section{1- ENUNCACÄO FUNDAMENTAL \\ 2- PROMESSA \\ 3- ESPECFFCACÄO DA PROMESSA \\ 4- INSCRIÇ̊̃O DE UM TERRTÓRD \\ 5- VALORES}

Figura 2. Projeto de marca de Semprini.

Fonte: Adaptado pelos autores a partir de Semprini (2006)

Como primeiro componente, o autor coloca a enunciação fundamental da marca, sendo "a verdadeira razão de ser, o fundamento de sua abordagem, a justificação ( $a$ priori) de sua legitimidade para existir”, pois para ele "na competição semiótica atual, cada marca deve sempre justificar sua existência, edificar sua legitimidade a partir de sua enunciação fundamental"; se perguntar e responder "Por que eu ao invés de nada?” (Ibidem, p. 159-160). O conceito torna-se uma das peças principais a sustentar as etapas seguintes.

Logo, é necessário que uma marca se posicione sempre em tom de criatividade, para que possa alcançar seus objetivos. Aqui podemos considerar que Bolt se afirma como corredor que representa seu país e carrega consigo uma série de valores que deverão ser apresentados a quem o assiste.

Em seguida, a enunciação fundamental deve transformar-se em promessa (quando a enunciação fundamental é orientada para o contexto social e público da marca; quando se passa da introspecção à projeção), seguido de sua especificação (momento em que elaborase seu caráter original). Bolt encontra sua enunciação fundamental na capacidade de promover um espetáculo - a ser justificado e especificado na possibilidade de descontração, renovação de partidas ganhas e do envolvimento.

A inscrição da promessa em territórios é quando coloca-se a marca como oferta, concretizando o projeto. Assim, o atleta insere-se como velocista em pistas de corrida, apesar de visar manifestar seus discursos também em diversos outros locais, expandindo sua presença para além das pistas. 
Já os valores da marca são as características e nuances que permitem a marca "figurativizar" sua abordagem, de lhe dar uma atitude própria e específica, de se coligar aos valores contextuais e socioculturais. $\mathrm{O}$ atleta, aqui, escolhe as características que irão sustentar e condicionar suas manifestações.

Após constituída essa instância de enunciação, a marca é capaz de gerar seus enunciados concretos. Para o autor, as manifestações de marca se organizam nos níveis dos valores, da narração e do discurso. Desenvolvemos a análise partindo desse princípio presente na Figura 3.

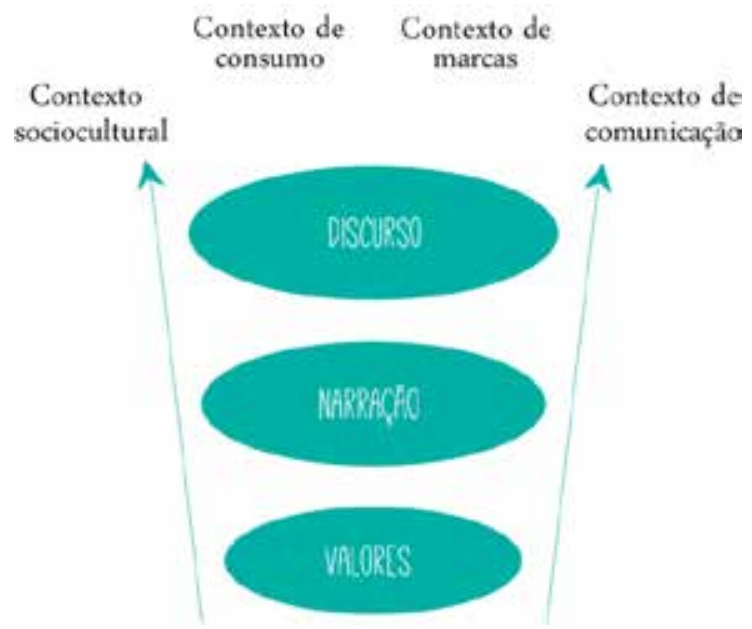

Figura 3. Organização semionarrativa do significado em seu contexto. Fonte: Adaptado pelos autores a partir de Semprini (2006).

No nível dos valores se encontram os valores fundadores da própria identidade da marca e o que atribui a ela um sentido. É o ponto de partida onde Bolt investe na descontração, intimidação e excentricidade, para se construir. Todos esses valores trazem para os telespectadores um sentimento de curiosidade e admiração, pois, através da aplicação deles, Bolt se constrói não só como marca, mas como alguém a ser respeitado.

No nível das narrativas (intermediário), os valores são organizados em forma de relatos. Bolt coloca-se numa narrativa esportiva, em pista de corrida, no contexto do evento olímpico. Mas também se insere nos mais diversos locais conforme está ilustrado na Figura 4.

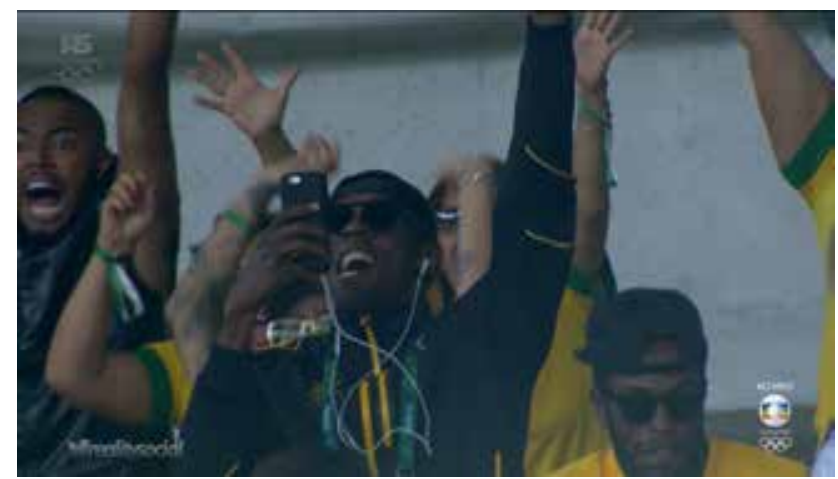

Figura 4. Usain Bolt na torcida do jogo Brasil vs. Alemanha, 2016. Fonte: Diário de Futebol, $2016^{2}$.

2. Disponível em: <https://goo.gl/UX5e3a>. Acesso em: $1^{\circ}$ fev. 2018. 
No nível discursivo é onde ocorre o enriquecimento da narrativa pelas figuras do mundo. Aqui o atleta manifesta seus valores fundamentais e mostra de fato o que é a marca Bolt, com suas especificidades e inovações. $\mathrm{O}$ atleta se constrói sobre a repetição de determinadas condutas e a criação de outras. Exemplos podem ser vistos na corrida de $100 \mathrm{~m}$ e a de $200 \mathrm{~m}$ e o comportamento durante as entrevistas. Em ambas as competições dança antes da corrida, porém de forma diferente. Na de $100 \mathrm{~m}$ tira foto com o mascote, mas ainda segue com determinados padrões, como o ato de fazer o sinal da cruz, sua pose característica e ir ao público.

Essas manifestações ajudam a gerar curiosidade nos que o assistem, pois, partindo da premissa de que ao assisti-lo haverá sempre ações esperadas e inusitadas, o público já se torna cativado por uma busca de algo mais a descobrir e pela sustentação daquilo que o atleta promete ser.

Ao pedir ao público que faça barulho e, em seguida, que faça silêncio, ao mesmo tempo que manifesta sua descontração, insere a intimidação nesse contexto (Figura 5). Destaca-se dos demais por ser o único a agir dessa forma.

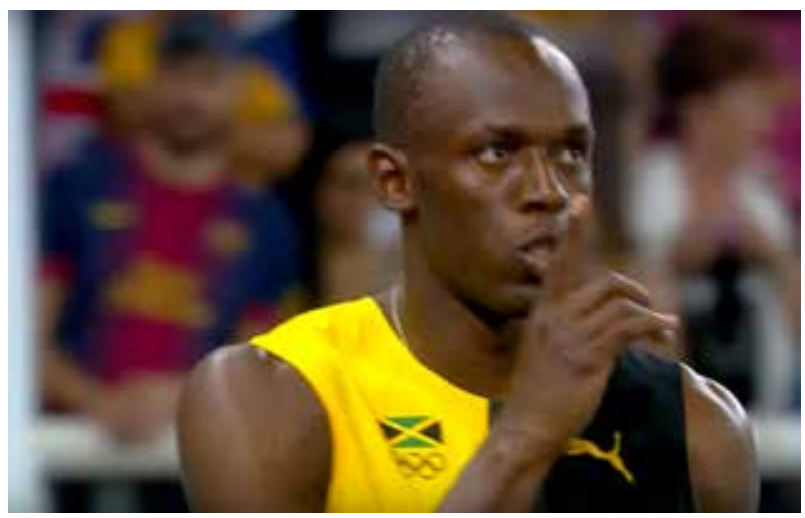

Figura 5. Corrida de Bolt nos $100 \mathrm{~m}, 2016$

Fonte: YouTube, $2016^{3}$

Isso também se aplica à entrevista à ESPN, na qual o atleta brinca com o repórter. Em ambas as ocasiões onde se esperava a "formalidade", traz sua excentricidade para a situação e carrega os valores mencionados anteriormente, produzindo uma quebra de comportamento do que era esperado (Figura 6).

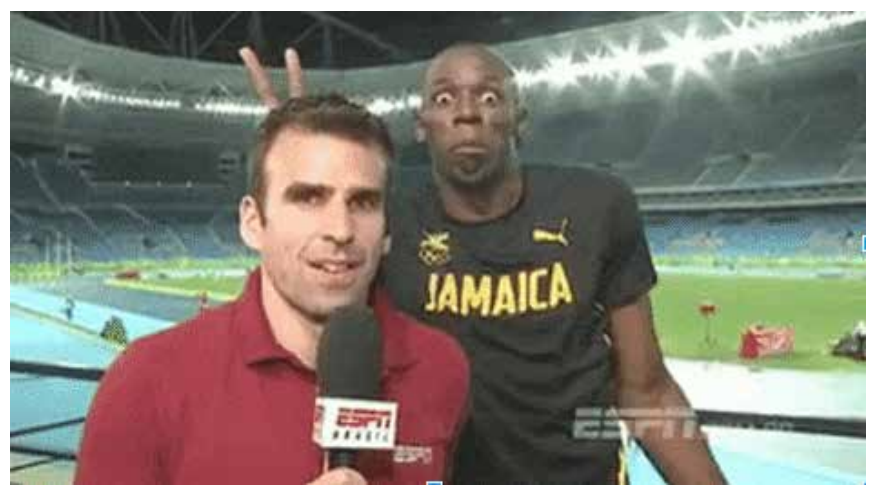

Figura 6. Entrevista de Usain Bolt à ESPN. Fonte: ESPN, 2016.

3. Disponível em: <https://goo.gl/nECCWh>. Acesso em: $1^{\circ}$ fev. 2018. 
Ao construir a comunicação de sua marca a um ambiente repleto por clichês e "modelos" básicos de comportamento, faz uma ruptura de estereótipos de competições e de como corredores devem se portar, reconstrói o imaginário daquilo que está consolidado como tal e cria um novo mundo a ser explorado.

Disperso em elementos narrativos, o destinatário, diante dessas manifestações, encontra os discursos como uma flexível forma de jogos de linguagem. Com a representação, criada de forma sociocultural (PERUZZOLO, 2015, p. 37-38), Bolt faz uso da capacidade abstrativa para concretizar sua marca, dirigindo-se de forma personalizada aos telespectadores.

Semprini (2006, p. 168) ainda evidencia que esse nível é o mais sensível do ambiente sociocultural aos modos de vida e ao comportamento dos receptores. O processo de criação do significado se dá com influência do contexto geral, como o contexto sociocultural, debates de opinião, contexto histórico, de consumo, os conhecimentos e informações que dispõe. Os receptores podem enquadrar e até mesmo influenciar os processos interpretativos da marca.

Outro exemplo da inovação trazida pelo atleta aparece em um registro icônico de uma das performances nos 100 metros rasos. Durante a competição, o fotógrafo o capturou sorrindo para a câmera, diante dos demais corredores. Essa foto acabou inspirando diversas piadas na internet e foi eleita pelo site B9 a "melhor foto dos Jogos Olímpicos” (MERIGO, 2016). Esse registro carrega, novamente, os valores e cria, no contexto de sua manifestação, condições de representações que extrapolam o imaginário de uma narrativa esportiva, pois apresenta o atleta aparentemente "tranquilo" em comparação aos demais corredores.

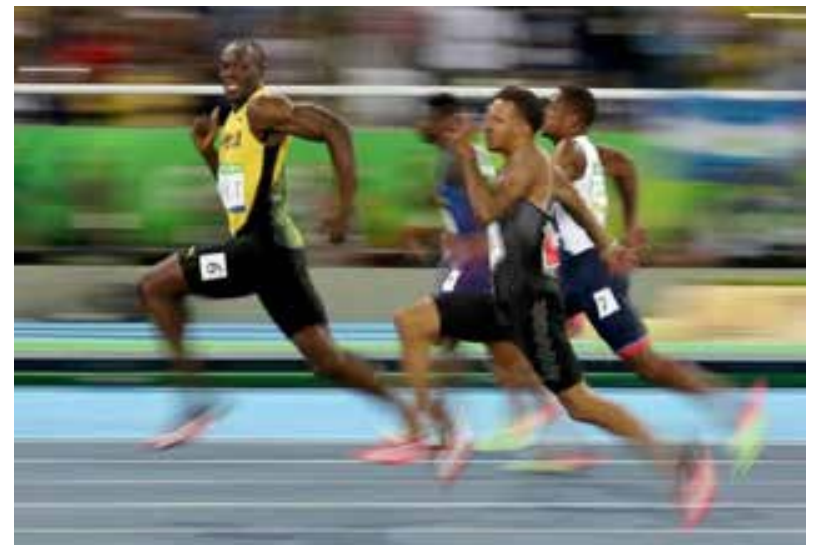

Figura 7. Bolt sorrindo durante a corrida de 100 m, 2016. Fonte: Site B9, $2016^{4}$.

Todas as normatizações de organização das corridas e entrevistas, com tudo o que já é conhecido e esperado, fazem parte do tipo de narrativa esportiva que o atleta está inserido. As ações de Bolt chamam atenção por conta das figuras que enriquecem a narrativa.

As manifestações o ajudam na criação e consolidação de sua identidade de marca. Demonstrando sua personalidade, dá abertura à difusão dela para os mais diversos meios, como nas propagandas e demais locais onde ele possa ser visto sob aspecto midiático. Demonstrando respeito a seu público, seja após as corridas, indo à escola de samba da Salgueiro ou interrompendo a

4. Disponível em: <https://goo.gl/qHzc2p>. Acesso em: $1^{\circ}$ fev. 2018. 
jornalista para ouvir o hino nacional dos Estados Unidos, cria uma intimidade para com eles e fica à vontade. As manifestações dão a ele a soma do fato de ser o velocista mais rápido do mundo com a de ser alguém que merece estar onde está, pela justificativa de carregar os valores que carrega.

\section{CONCLUSÃO}

Podemos concluir, tendo em vista as dimensões que formam uma marca na contemporaneidade - a natureza semiótica, relacional e evolutiva - que uma pessoa pode utilizar dessa lógica para criar sua marca pessoal. Propor discursos relevantes é possível quando quem utiliza dessa intenção tenha a atenção voltada para as dimensões-chave, para a criação de um projeto marca consistente e original que tenha sua sustentação nas adversidades, de sua escolha para a formulação de valores, da organização em uma narrativa e de seu enriquecimento discursivo.

Analisando pelo modelo de Semprini, constatamos que Bolt constrói sua marca pessoal sustentando-se, principalmente, nos valores de descontração, intimidação, excentricidade para com o público. Simplificadamente, podemos pegar de exemplo o modelo apresentado por Semprini e considerar as manifestações da marca Bolt dentro de contextos, como o contexto sociocultural, contexto de comunicação, de "consumo", de corrida, estruturando conforme ilustra a Figura 8.

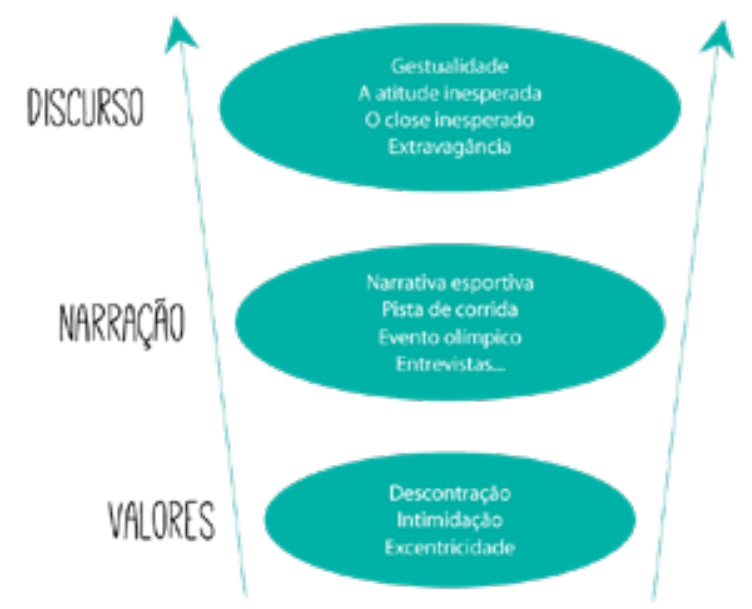

Figura 8. Organização semionarrativa do significado.

Fonte: Adaptado pelos autores a partir de Semprini (2006)

Bolt ainda utiliza como ajuda os recortes midiáticos televisivos, jornalísticos e contextuais. Assim, constrói aos poucos sua marca pessoal, buscando a identificação por parte dos telespectadores e a diferenciação como velocista.

Em suma, podemos dizer que a capacidade de construir universos simbólicos que gerem a identificação de marca deve ser seguido por uma enunciação concreta. A originalidade sobre formas gerais é o que torna a marca um potencial expansivo e de crescimento.

Diante da complexidade do fenômeno me brand, é notório que ele ainda há de ser debatido e reformulado por aqueles que o estudam e/ou virão a utilizá-lo. Entretanto, o percurso gerativo de sentido se sustentará sempre visando ao público que irá encontrar, e a possibilidade de envolvimento torna-se um alicerce para uma comunicação diferenciada, independentemente dos meios pelos quais a mensagem é transmitida. 


\section{REFERÊNCIAS}

ARRUDA, C. F. De que é feita uma me brand? Estudo de caso sobre o capital social da blogueira Camila Coelho. 2015. 68 f. Trabalho de Conclusão de Curso (Bacharelado em Comunicação Social - Publicidade e Propaganda) - Universidade Federal de Santa Maria, Santa Maria, 2015.

CASAQUI, V. Processos de representação e referencialidade na publicidade contemporânea: mundo do trabalho, cidade, beleza e ativismo social. Signos do Consumo, São Paulo, v. 1, n. 2, p. 159-172, 2009.

KOTLER, P. Administração de marketing. São Paulo: Atlas, 1998.

MARTINS, J. R. Branding: um manual para você criar, gerenciar e avaliar marcas. São Paulo: GlobalBrands, 2006. Disponível em: <https://goo.gl/nSz2E>. Acesso em: 5 out. 2016.

MERIGO, C. Usain Bolt sorrindo nos 100 metros rasos já é a melhor foto dos jogos Rio 2016. B9, São Paulo, 2016. Disponível em: <https://goo.gl/KclZ86>. Acesso em: 1 out. 2016.

MOTA, C. Samba, Bolt! Jamaicano dança com passistas e tira selfie durante coletiva. Globo Esporte, Rio de Janeiro, 8 ago. 2016. Disponível em: <https://goo.gl/oc1MLt>. Acesso em: 10 out. 2016.

OZANIAN, M. 10 atletas com as marcas mais valiosas de 2016. Forbes Brasil, São Paulo, 27 out. 2016. Disponível em: <https://goo.gl/kLG6fh>. Acesso em: 21 abr. 2017.

PARA se tornar o homem mais rápido do mundo... Gatorade Brasil, 2016. Facebook. Disponivel em: <https://goo.gl/VzQKcl>. Acesso em: 14 out. 2016.

PEREZ, C. Signos da marca: expressividade e sensorialidade. São Paulo: Pioneira Thomson Learning, 2004.

PERUZZOlo, A. C. Elementos de semiótica da comunicação. Jundiaí: Paco, 2015.

SEMPRINI, A. A marca pós-moderna: poder e fragilidade da marca na sociedade contemporânea. São Paulo: Estação das Letras, 2006. 